\title{
Spectacular presence of parasitic males of Strongyloides stercoralis in human host
}

\section{Feleke Eriso}

Biomedical Stream, Department of Biology, College of Natural and Computational Science, Dilla University, Dilla, Ethiopia.

\author{
Accepted 14 May, 2018
}

E-mail: feleke.eriso@yahoo.com, dilla@ethionet.et. Tel: +251916514682, +251463312097. Fax: +251463312674.

\section{Dear Editor,}

In the entire world, it was believed and reported that the parasitic male did not exist in the body of human host, concluding that the parasitic generation of Strongyloides stercoralis in human host consisted of the parasitic female only that used to reproduce by parthenogenesis in the absence of parasitic male (Mitreva et al., 2004; Concha et al., 2008; Hunter et al., 2008; Paniker, 2007; Bogitsh et al., 2005; Dillard et al., 2007; Keiser and Nutman, 2004; Dionisio et al., 2000; Dionisio et al., 2000; Massey, 2003; Garg et al., 2005).

The real parasitic males of $S$. stercoralis were isolated from fresh stool samples of infected student children. The conte $\mathrm{nt}$ of this report is displaying the presence of parasitic males of $S$. stercoralis in human hosts. You will also find out that $t$ he term "curved tail" was not a correct taxonomic term for the parasitic males of $S$. stercoralis. The most important and practically investigated correct morphological taxonomic characteristic of the parasitic males of $S$. stercoralis that can be used to differentiate them from the parasitic females in human hosts is the ventrally curved or coiled posterior part of body as the curvature goes beyond the cloaca in the anterior direction. This is so because what is called a tail in a nematode is the posterior part beginning from the cloaca or anus. The posterior parts of the parasitic adult males of $S$. stercoralis were microphotographed under higher magnification objectives in order to see the structural details of male genitals and because the males are differentiated from the parasitic adult females by the characteristic of ventrally curved or coiled posterior part of body. When the higher magnifications are used the entire body of the worm cannot be within the field of vision; therefore, only the posterior part of the worm was microphotographed with the high power objective lens to see the details of interest (Figures 1 to 11). The whole body of taxonomic morphology of the adult parasitic males is also made available here below with the help of low power objective lens (Figures 12 to 17). There are variations in the degree of curvature of the posterior part of body in the parasitic males (that is, from simple curve up to coiling). All the specimens forwarded here below are isolated from fresh stool samples of participant student children. This report has spectacularly ascertained that the parasitic males of $S$. stercoralis are found in human host like the parasitic females of it.

Keywords: Spicule, cloaca, parasitic male, curved posterior body part, human host, Strongyloides stercoralis.

\section{INTRODUCTION}

In the entire world, it was believed and reported that the parasitic male did not exist in the body of human host, concluding that the parasitic generation of Strongyloides stercoralis in human host consisted of the parasitic female only that used to reproduce by parthenogenesis in the absence of parasitic male (Mitreva et al., 2004; Concha et al., 2008; Hunter et al., 2008; Paniker, 2007; Bogitsh et al., 2005; Dillard et al., 2007; Keiser and Nutman, 2004; Dionisio et al., 2000; Dionisio et al., 2000; Massey, 2003; Garg et al., 2005).

Modern textbooks and articles of journals are being used with the concept that parasitic males of $S$. stercoralis never exist in the body of human host (Siddiqui and Berk, 2001; Ramanathan and Nutman, 2008; Jayshree et al., 2001; Kim et al., 2005; Fardet et al., 2007; Kerepesi et al., 2007; Rahif et al., 2002). 


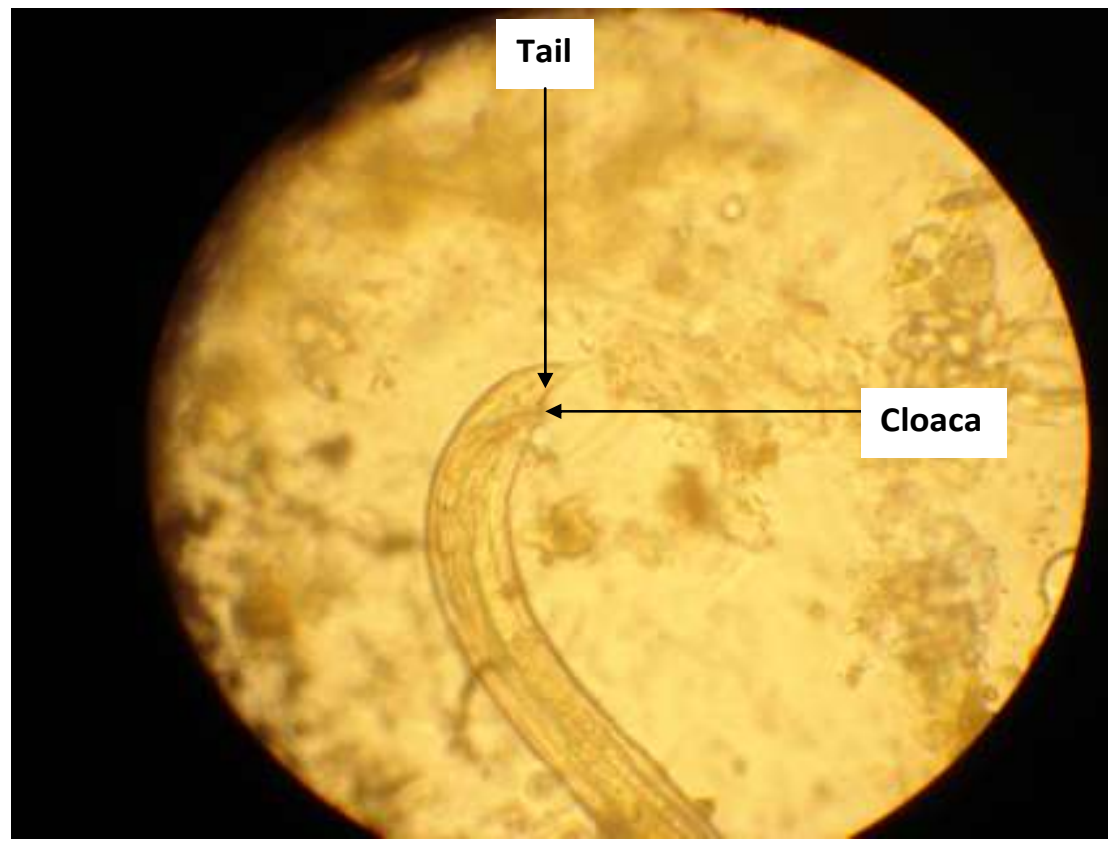

Figure 1. What is called cloaca in parasitic males, is known as anus in the parasitic females of $S$. stercoralis.

Tail is the posterior side part from cloaca.

The tail part of body begins from cloaca/anus.
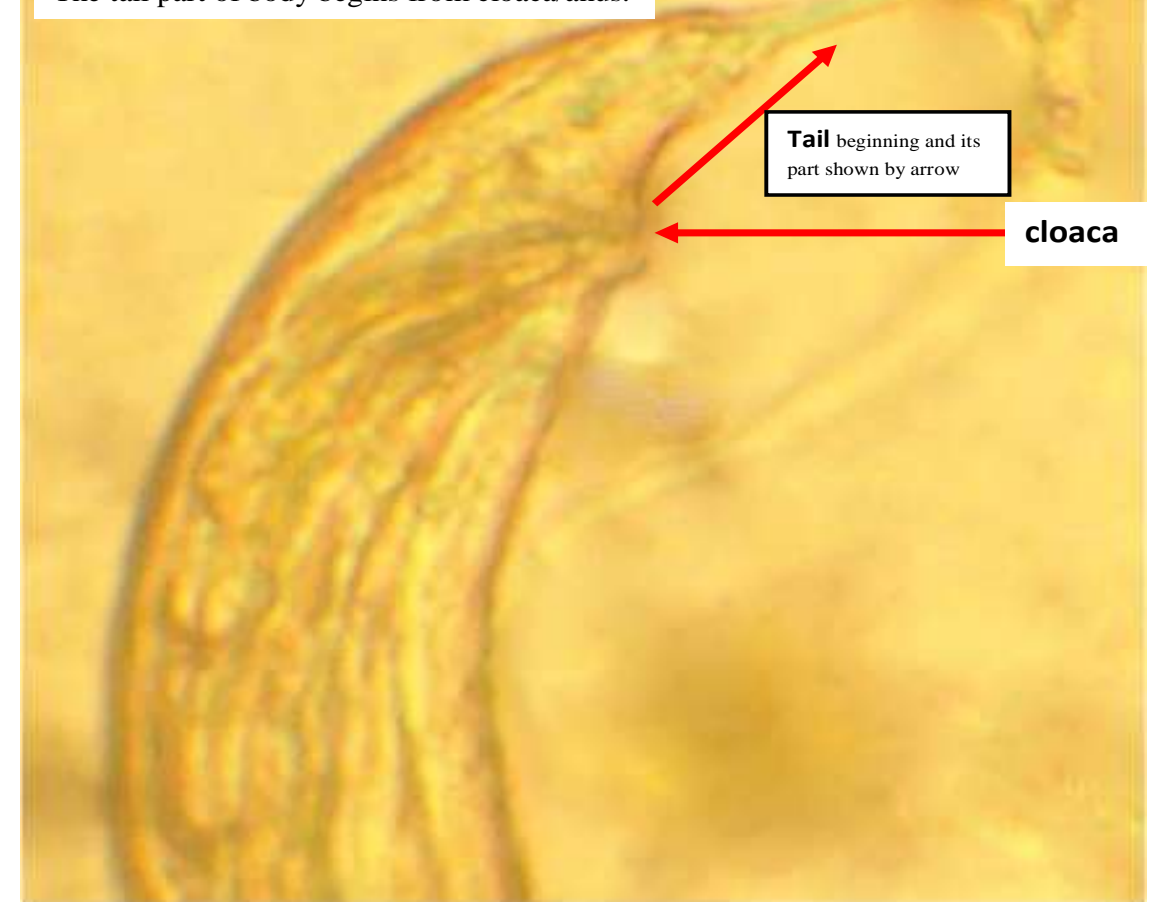

Figure 2. The anus is called cloaca in the parasitic males, because it is a common outlet of the products of both reproductive tract and digestive tract (that is, a common exit of both sperm, and feces). On the other hand, what is known as cloaca is termed anus in the parasitic females as it is the exit only for the products of the digestive tract. The tail of these parasitic males and of other nematodes consists of the body part of the worm beginning from the cloaca (or anus) up to the posterior terminal tapering end. 


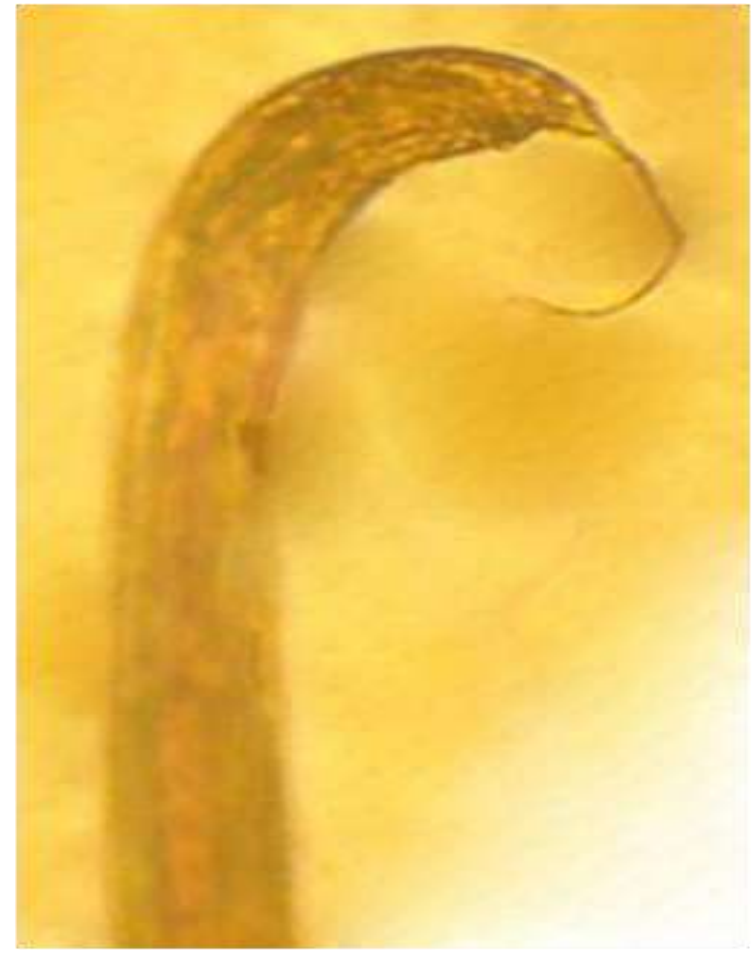

Figure 3. Why the term "curved tail" is an unfit term to explain the taxonomic morphology of the parasitic males of $S$. stercoralis?

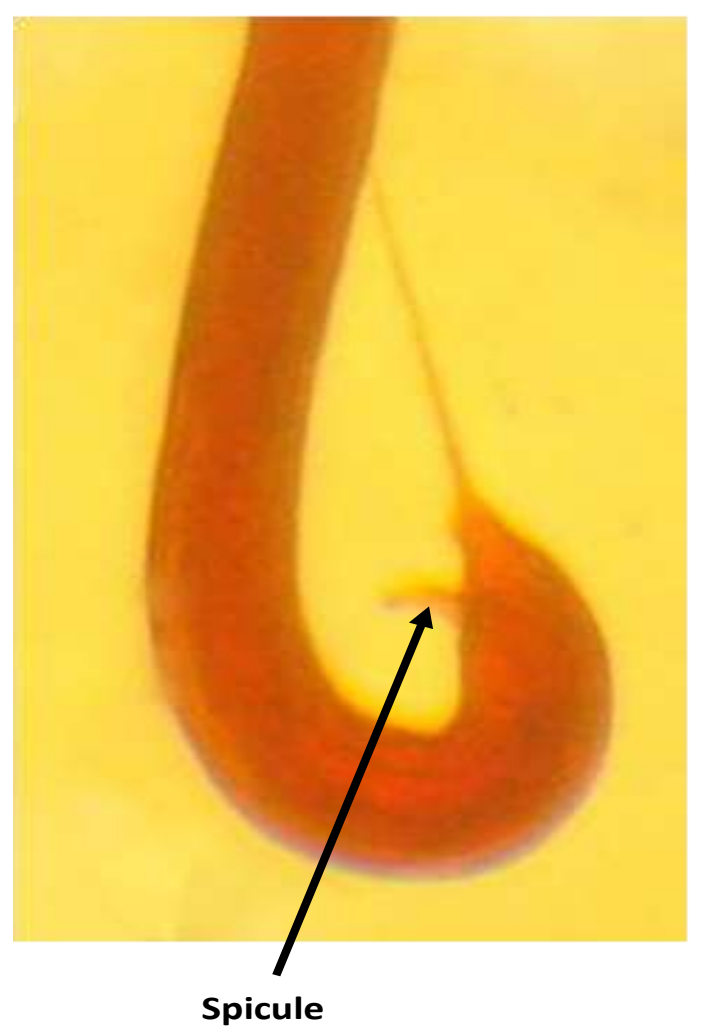

Figure 5. It is only the posterior body part of male Strongyloides stercoralis that is curved.

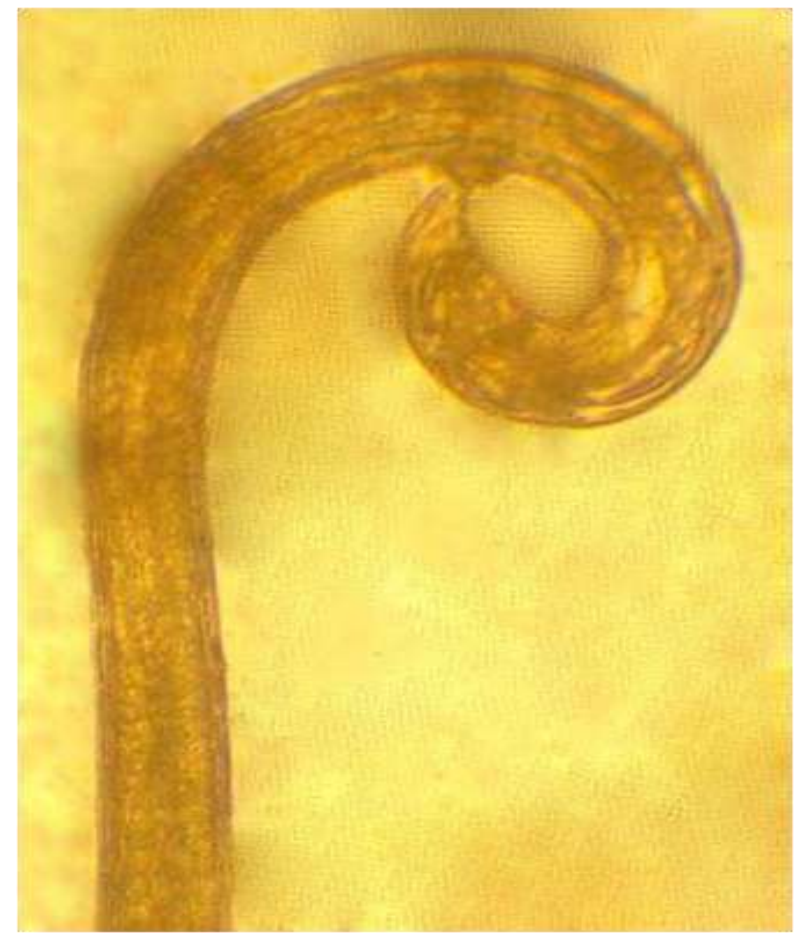

Figure 4. Why the term "curved or coiled posterior part of body" is correct and not the "curved tail" for the taxonomic morphology of parasitic males in S. stercoralis?

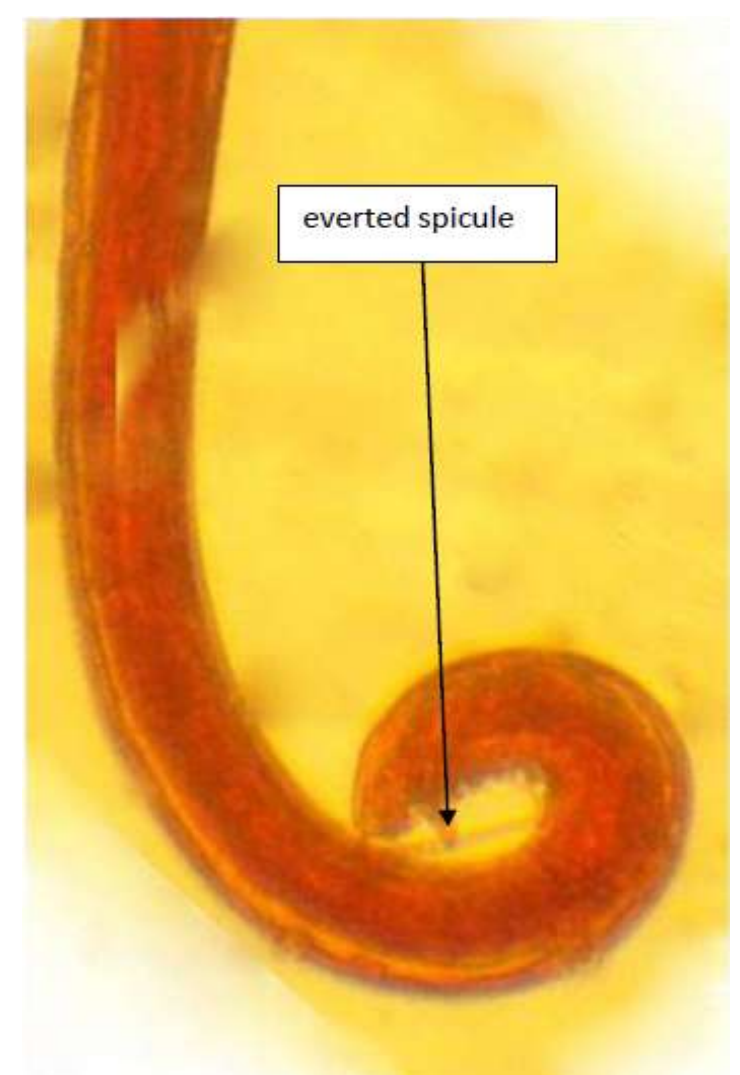

Figure 6. Is it only the tail part of body that is curved? 


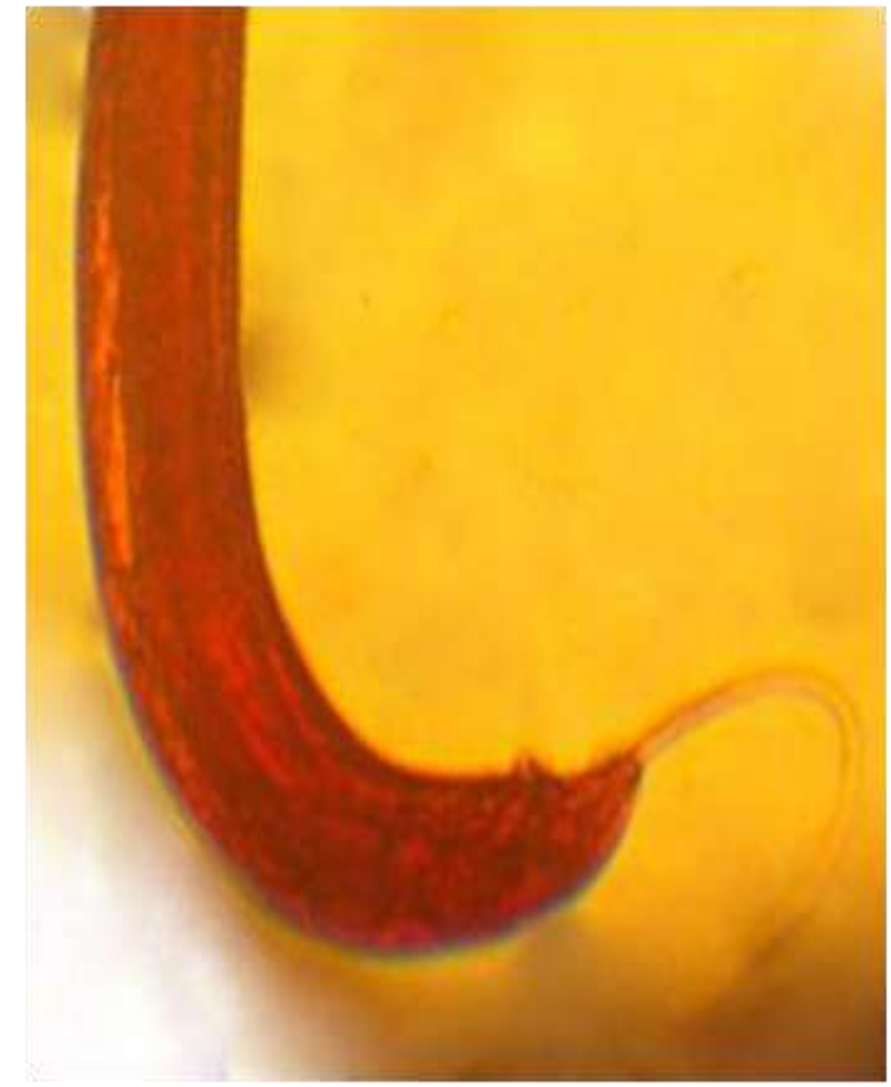

Figure 7. Observe the tip of spicule everting from the cloaca in this male.

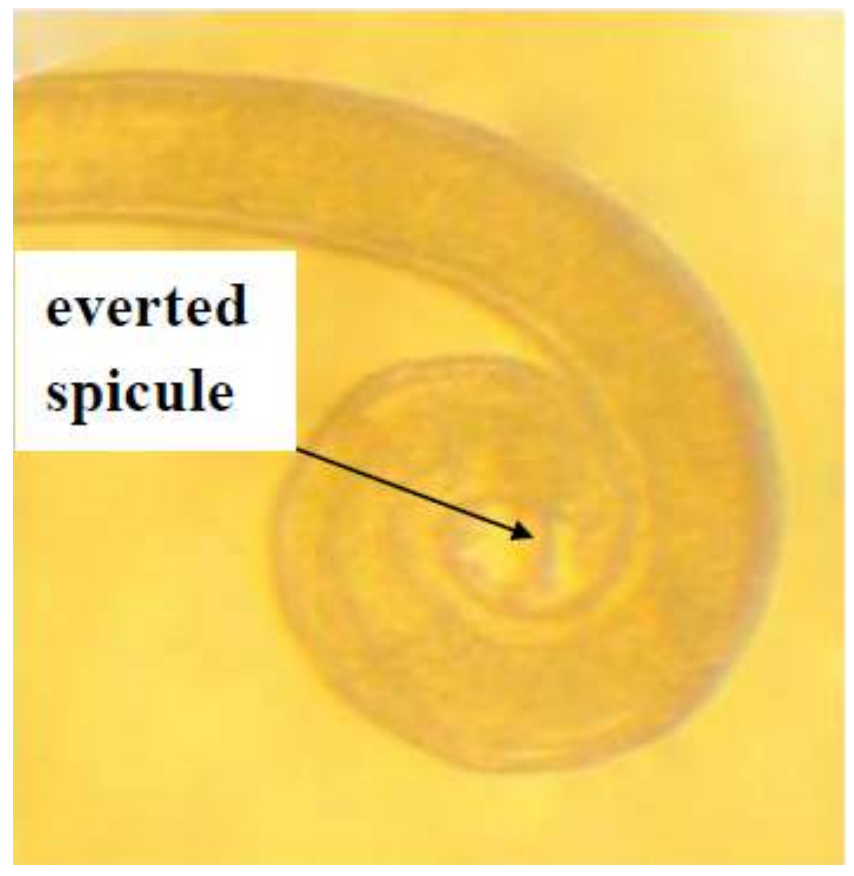

Figure 9. What do you feel about the unfitness of the term "curved tail" for the taxonomic morphology of parasitic males in S. stercoralis, including this parasitic male?

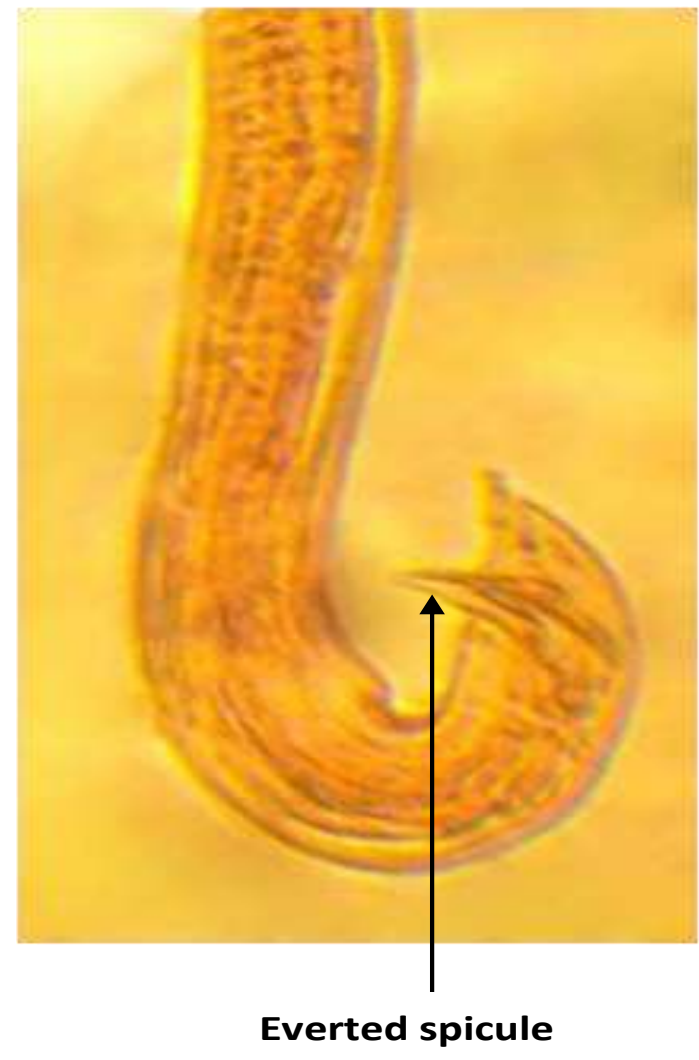

Figure 8. Do you accept the term "curved tail" as an appropriate term for this taxonomic morphology?

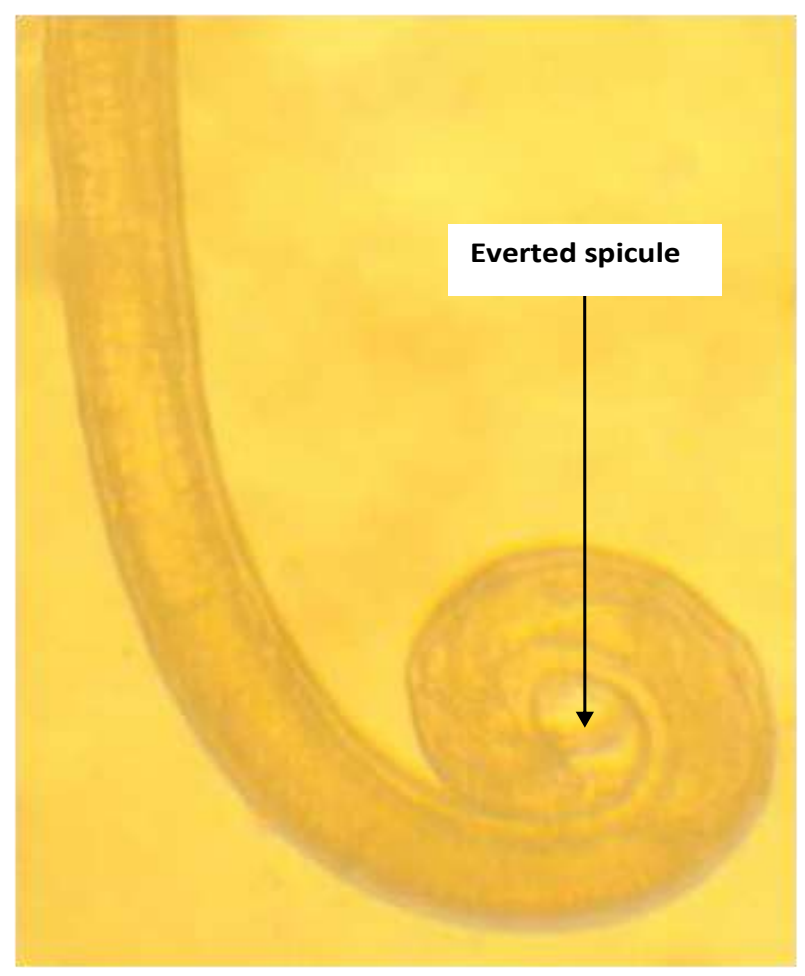

Figure 10. Observe the everted spicule in this coiled posterior part of body of the adult parasitic male. 


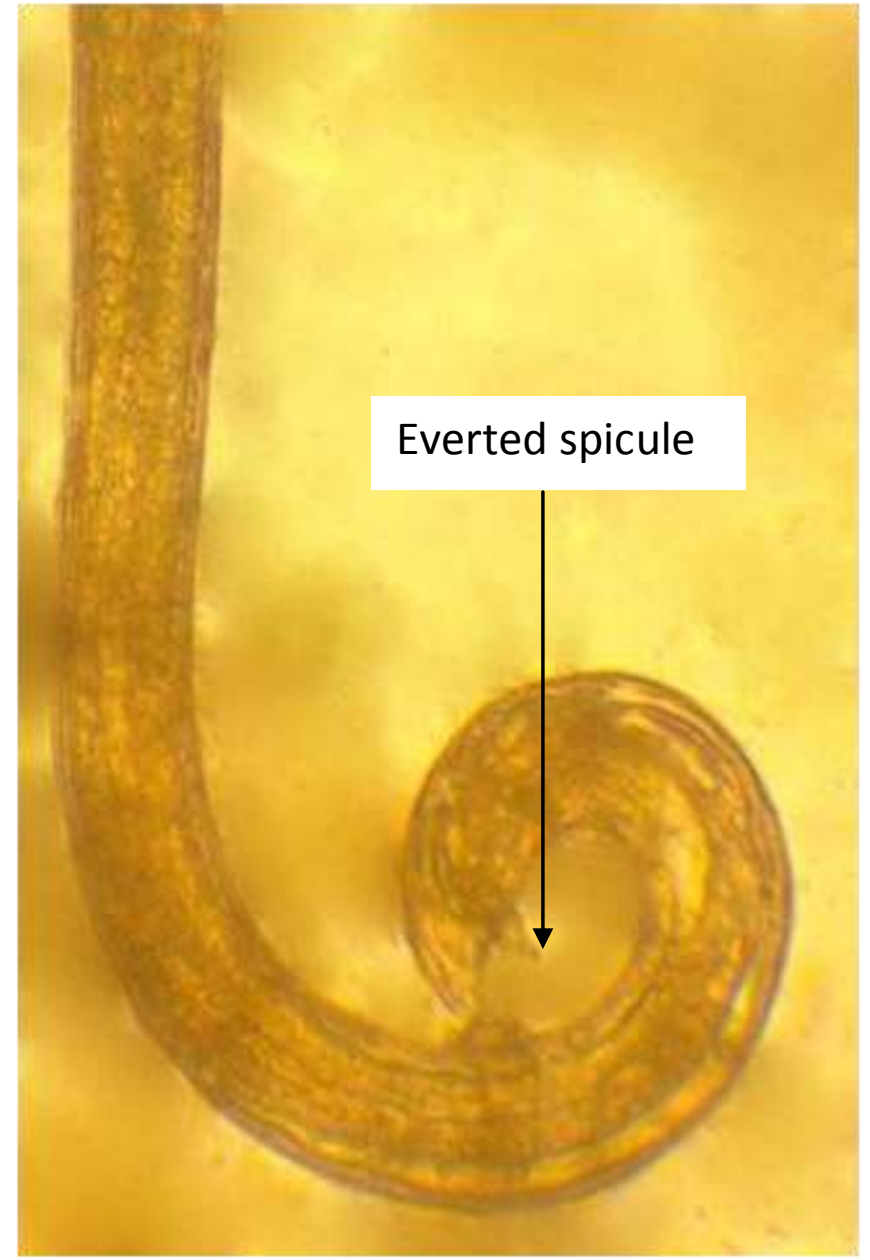

Figure 11. Observe the everted spicule from the spicule pouch found inside cloaca.

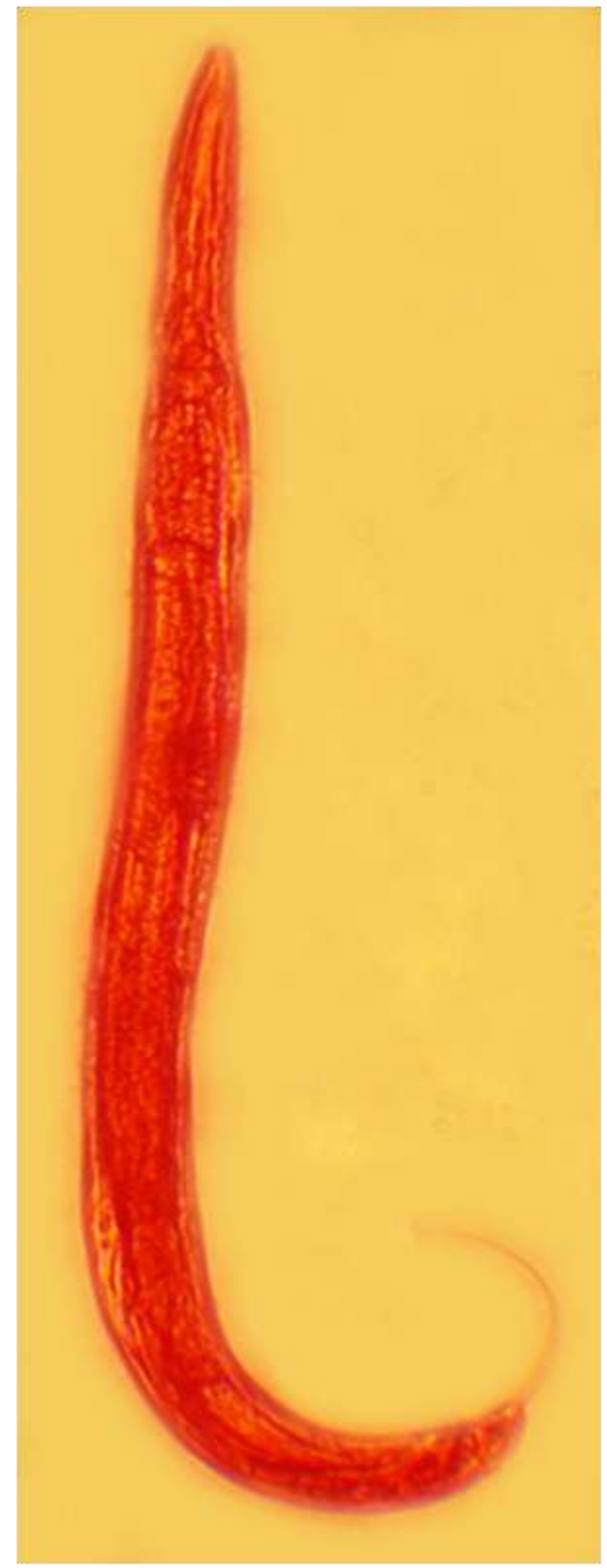

Figure 12. Based on your cumulative observation, should the term "curved tail" be replaced by the term "curved or coiled posterior part of body"? Your answer must be Yes. 


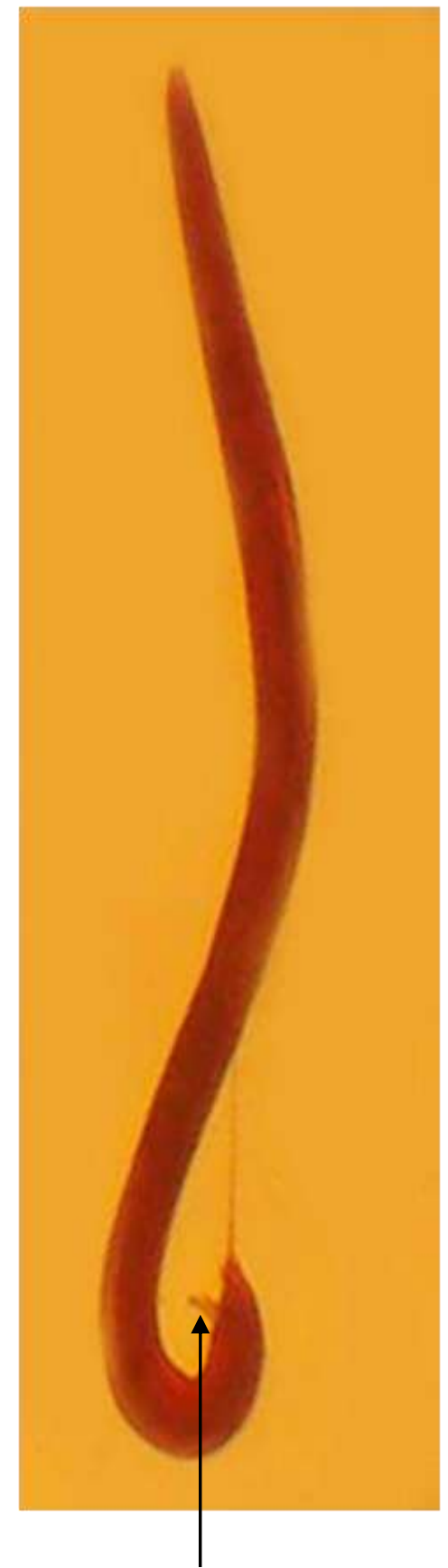

\section{Everted spicule}

Figure 13. Are you able to observe the everted spicule that is everted at times of breeding for copulation and fertilization?

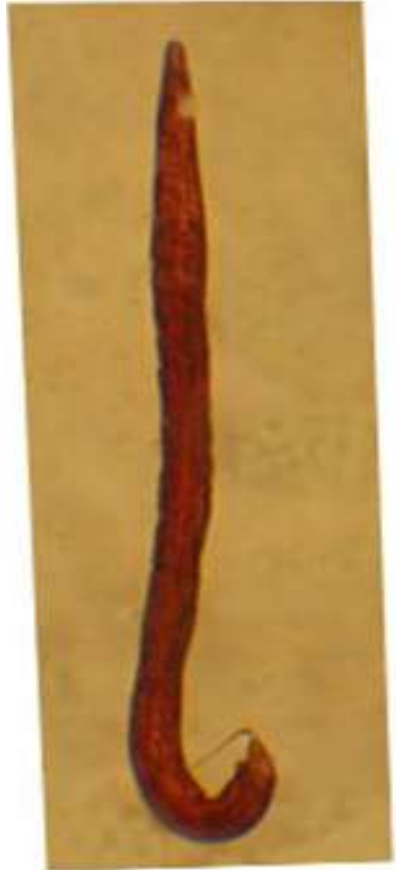

Figure 14. Is the nature of curvature, in the posterior part of body, of this parasitic male similar to those of all others?

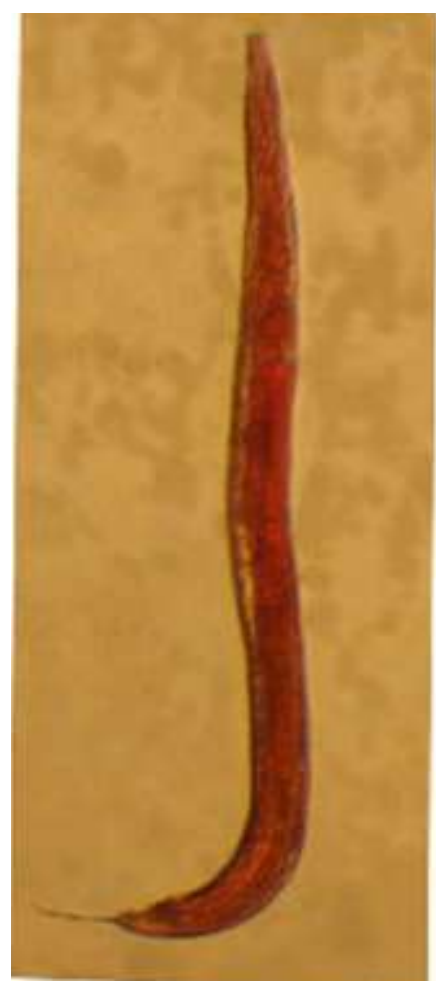

Figure 15. What about the nature of curvature, in the posterior part of body, of this parasitic male? 

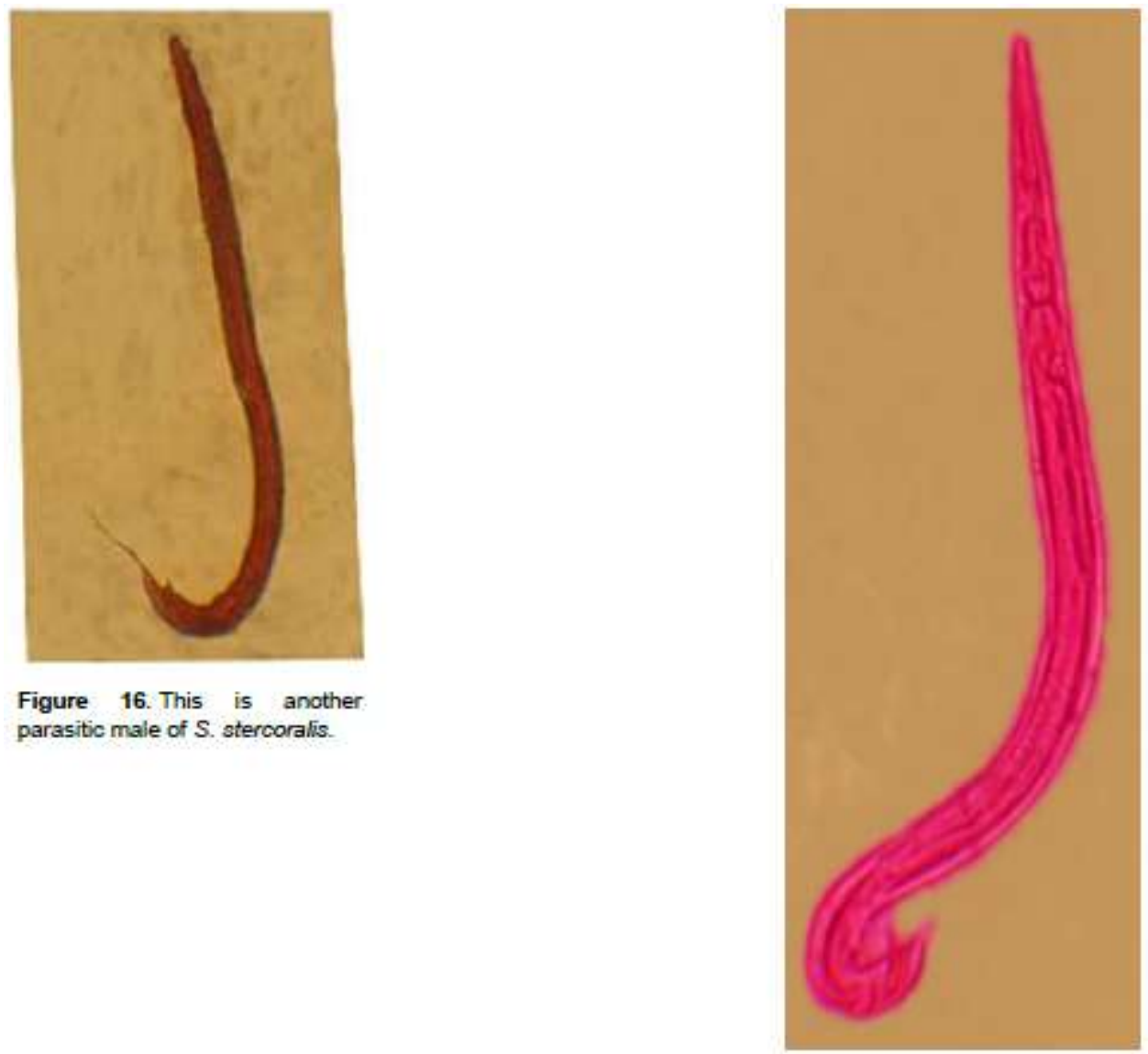

Figure 17. Please, give your conclusion about the correct term which fits the taxonomic morphology of parasitc males that differentiates them from parasitic females of S. stercoralis.

It is only the posterior body part of male Strongyloides stercoralis that is taxonomically curved to varying degrees, from slight curvature upto more than $360^{\circ}$ coiling (Figure 5). The spicule, with its tips that resemble the tips of a forcep, is used to open the vulva of the female to release male gametes into the female's reproductive tract at times of breeding and it is only at times of breeding that spicule is everted through cloaca from the spicule pouch. In S. stercoralis the exit of feces is called anus in females as the reproductive and digestive tracts do not have a common exit in females unlike in males. In males of $S$. stercoralis, the exit of the reproductive and digestive tracts is the same and such a common exit including this of male $S$. stercoralis is known as cloaca.

Comment on the term "curved tail" about its being correct or not for this taxonomic morphology in relation to the region of body (Figure 10).

Did you prove that the term "curved tail" was a wrong term to use for the taxonomic morphology of parasitic males in S. stercoralis that used to be harbored in human hosts? (Figure 11)

Please, note the boundary between the main body and the tail in an individual parasitic male of $S$. stercoralis (Figures 1 and 2).

Did you ascertain the fact that there are variations in the extent (degree) of curvature in the posterior body-part of the parasitc males of $S$. stercoralis? (Figure 16)

\section{CONCLUSION}

This report has spectacularly ascertained that the parasitic males of S. stercoralis are found in human host like the 
parasitic females of it. The curvature of posterior body part in males of $S$. stercoralis varies from a slight bending up to coiling of more than $360^{\circ}$. The curvature of posterior body part is of the major morphological criteria to distinguish males from female of $S$. stercoralis.

\section{Ethics}

No ethical error is seen or committed in the execution of this study.

\section{Competing interests}

I declare that I do not have any competing interests with anybody.

\section{ACKNOWLEDGEMENTS}

I am deeply grateful to the scientists acknowledged in the text and list of references of this paper for their providing me with confidential data (that can be counterchecked for their correctness with the observable facts in the natural environment) as well as from modern textbooks and articles of reputable journals. Science cannot develop without science.

\section{REFERENCES}

Bogitsh BJ, Carter CE, Oeltmann TN, 2005. Human parasitology. 3rd ed., USA; Academic press; 334-339.

Concha R, Harrington WJR, Rogers Al, 2008. Intestinal strongyloidiasis: recognition, management, and determinants of outcome. J Clin Gastroenterol, 39: 203-211.

Dillard KJ, Saari SAM, Anttila M, 2007. Strongyloides stercorali infection in a Finnish kennel. Acta Vet Scand, $49: 37$

Dionisio D, Manneschi LL, Lollo SD, Orsi A, Tani A, Esperti F, 2000. Strongyloides stercoralis: ultrostructural study of newly hatched larvae within human duodenal mucosa. J Clin Pathol, 53: 110-106.

Fardet L, Genereau T, Poirot JL, Guidet B, Kettaneh A, Cabane L, 2007. Severe strongyloidiasis in corticosteroid-treated patients: case series and literature review. J Infect, 54: 18-27.

Garg PK, Perry S, Dorn M, Hardcastle L, Parsonnet J, 2005. Risk of intestinal helminth and protozoan infection in a refugee population. Am J Trop Med Hyg, 73(2): 386-391.

Hunter CJ, Petrosyan M, Asch M, 2008. Dissemination of Strongyloides stercoralis in a patient with systemic lupus erythematous after initiation of albendazole: a case report. J Med Case Reports, 2: 156.

Jayshree RS, Hema S, Govind B, Suresh TM, 2001. Strongyloides stercoralis eggs in the stools during anticancer therapy. Indian J Gastroenterol; 20: $160-161$.

Keiser PB, Nutman TB, 2004. Strongyloides stercoralis in the immunocompromised population. Clin Microbiol Rev, 17(1): $208-217$.

Kerepesi LA, Hess JA, Leon O, Nolan TJ, Schad GA, Abraham D, 2007. Toll-like receptor 4(TLR4) is required for protective immunity to larval Strongyloides stercoralis in mice. Microb Infect, 9: 28-34.

Kim J, Joo HS, Ko HM, Na MS, Hw ASH, Im JC, 2005. A case of fatal hyperinfective strongyloidiasis with discovery of autoinfective filariform larvae in sputum. Korean J Parasitol, 43: 51-55.

Massey HCJ, Nishi M, Chaudhary K, Pakpout N, Lok JB, 2003. Structure and developmental expression of Strongyloides stercoralis. Int J Parasitol, 33: 1537-1544.

Mitreva M, McCarter JP, Martin J, Dante M, Wylie T, Chiapelli B, Pape D, Clifton SW, Nutman TB, Waterston RH, 2004. Comparative genomics of gene expression in the parasitic and free-living nematodes Strongyloides stercoralis and Caenorhabditis elegans. Genome Res, 14(2): 209-220.

Paniker CKJ, 2007. Textbook of medical parasitology. 6th ed., New Delhi; Jaypee Brothers Medical Publishers; pp: 169-174.

Rahif RH, Emara GY, Al-saqur IM, 2002. Epidemiological study of intestinal nematodes in dogs in Basrah (Iraq): prevalence of helminthic ova in the fecal deposits. Iraqi J Vet Sci, 16: 71-79.

Ramanathan R, Nutman TB, 2008. Strongyloides stercoralis infection in the immunocompromised host. Japan J Parasitol, 10(2): 105-110.

Siddiqui AA, Berk SL, 2001. Diagnosis of Strongyloides stercoralis. Clin Infect Dis, 33(7): 1040-1047. 